\title{
Disulfide Bond Formation in the Mammalian Endoplasmic Reticulum
}

\author{
Neil J. Bulleid \\ Institute of Molecular, Cellular and Systems Biology, College of Medical Veterinary and Life Sciences, Davidson \\ Building, University of Glasgow, Glasgow G12 8QQ, United Kingdom \\ Correspondence: neil.bulleid@glasgow.ac.uk
}

The formation of disulfide bonds between cysteine residues occurs during the folding of many proteins that enter the secretory pathway. As the polypeptide chain collapses, cysteines brought into proximity can form covalent linkages during a process catalyzed by members of the protein disulfide isomerase family. There are multiple pathways in mammalian cells to ensure disulfides are introduced into proteins. Common requirements for this process include a disulfide exchange protein and a protein oxidase capable of forming disulfides de novo. In addition, any incorrect disulfides formed during the normal folding pathway are removed in a process involving disulfide exchange. The pathway for the reduction of disulfides remains poorly characterized. This work will cover the current knowledge in the field and discuss areas for future investigation.

$\mathrm{O}^{\mathrm{n}}$ ne of the characteristics of proteins that enter the secretory pathway is that they frequently contain covalent linkages called disulfide bonds within and between constituent polypeptide chains. The presence of these linkages is thought to confer stability when secreted proteins are exposed to the extracellular milieu or when membrane proteins are recycled through acidic endocytic compartments. In addition to structural disulfides it is now clear that a number of proteins use the formation and breaking of disulfides as a mechanism for regulation of activity (Schwertassek et al. 2007). Hence, it is important that we have a clear understanding of how correct disulfides are formed within proteins both during the protein folding process and to regulate protein function. The focus of this article will be on how correct disulfides are introduced into proteins within the secretory pathway, specifically within the endoplasmic reticulum (ER) during folding and assembly.

The formation of disulfides within polypeptides begins as the protein is being cotranslationally translocated into the ER (Chen et al. 1995). The initial collapse of the polypeptide and formation of secondary structure brings cysteine residues into close enough proximity for them to form disulfides. Correct disulfide formation requires enzymes to both introduce disulfides between proximal cysteines and to reduce disulfides that form during folding but that are not present in the final native structure (Jansens et al. 2002). In addition, proteins that do not fold correctly are targeted for degradation and may require their disulfides to be broken before dislocation across the ER membrane

Editors: Susan Ferro-Novick, Tom A. Rapoport, and Randy Schekman

Additional Perspectives on The Endoplasmic Reticulum available at www.cshperspectives.org

Copyright (C) 2012 Cold Spring Harbor Laboratory Press; all rights reserved; doi: 10.1101/cshperspect.a013219

Cite this article as Cold Spring Harb Perspect Biol 2012;4:a013219 


\section{N.J. Bulleid}

into the cytosol (Ushioda et al. 2008). Hence, there must be a reduction and oxidation pathway present in the ER to ensure that native disulfides form and nonnative disulfides are broken during protein folding.

Central to both reduction and oxidation pathways is the protein disulfide isomerase (PDI) family of enzymes (Ellgaard and Ruddock 2005) that are capable of exchanging disulfides with their substrate proteins (Fig. 1). Whether disulfide exchange results in the formation or breaking of a disulfide depends on the relative stability of the disulfides in the enzyme and substrate. To drive the formation of disulfides, the PDI family member must itself be oxidized. It is now clear that there are a number of ways for the disulfide exchange proteins to be oxidized by specific oxidases. Importantly, these oxidases do not introduce disulfides into nascent polypeptide chains; rather, they specifically oxidize members of the PDI family. The exception to this rule is the enzyme quiescin sulfydryl oxidase (QSOX; see below). The pathway for disulfide reduction is not as well characterized. It is known that the PDI family members can be reduced by the low molecular mass thiol glutathione (GSH) (Chakravarthi and Bulleid 2004; Jessop and Bulleid 2004; Molteni et al. 2004) but no enzymatic process for reduction has been identified. The glutathione redox balance within the ER is significantly more oxidized than in the cytosol (Hwang et al. 1992; Dixon et al. 2008), indicating that GSH is actively oxidized to glutathione disulfide either during the reduction of PDI family members or by reducing disulfides in nascent polypeptides directly. However, there is currently no clear indication as to how glutathione disulfide is itself reduced.

Both the formation and breaking of disulfides can be thought of as electron transport pathways that require suitable electron acceptors or donors to drive the flow of electrons. For the purposes of this article the two pathways will be discussed separately, but it should be appreciated that each pathway occurs within the same organelle so the possibility of crossover between them is real. Whether futile redox reactions occur between the pathways is unclear but any

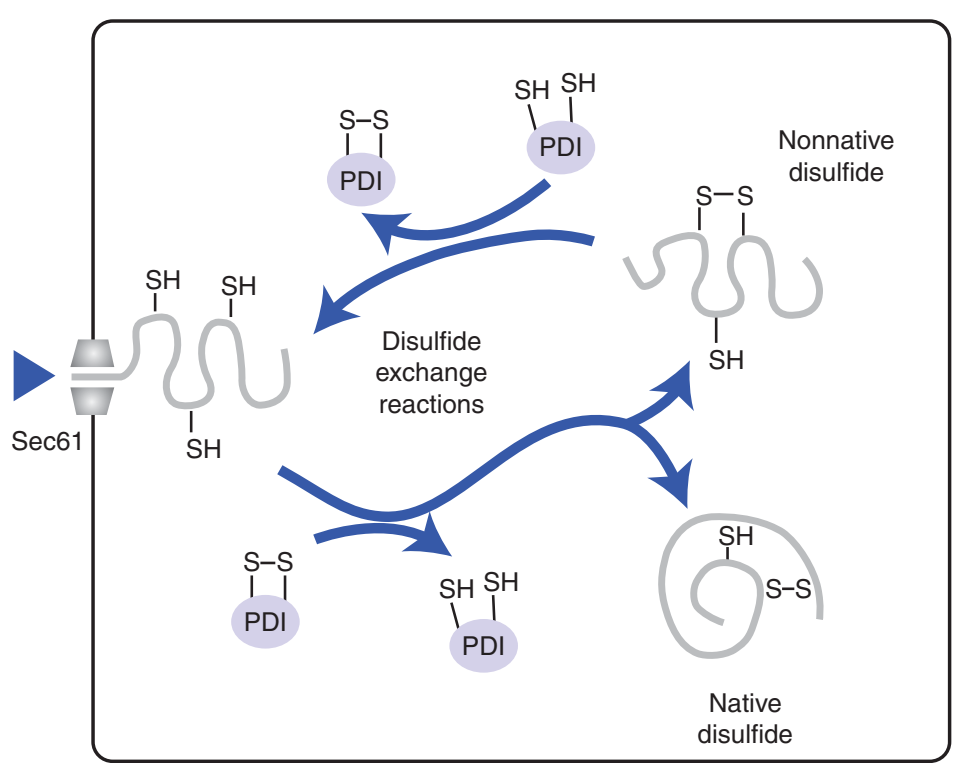

Figure 1. PDI family of enzymes catalyzes disulfide exchange reactions in the endoplasmic reticulum. Nascent polypeptide chains are cotranslationally translocated across the ER membrane whereupon cysteines in close proximity can form disulfides. The reaction is catalyzed by members of the PDI family (depicted as PDI) by a disulfide exchange reaction resulting in the reduction of the PDI active site. If nonnative disulfides are formed these can be reduced by the reverse disulfide exchange reaction, resulting in the oxidation of the PDI active site. 
kinetic segregation of the pathways will be highlighted where it is known to occur.

\section{THE OXIDATIVE PATHWAY}

Our understanding of how disulfides are formed within the ER has advanced rapidly over the last few years. It is now clear that there are several pathways in mammalian cells to drive the formation of disulfides de novo (Bulleid and Ellgaard 2011). We will look at these pathways individually, most of which involve a two-step process; the specific oxidation of a PDI family member followed by transfer of the disulfide to the nascent polypeptide chain.

\section{ER Oxidase 1}

In lower eukaryotes such as yeast, a single protein (Erolp) (ER oxidase 1) is both necessary and sufficient to catalyze disulfide formation in the disulfide exchange protein PDIp (Frand and Kaiser 1998; Pollard et al. 1998). The pathway for electron flow in the Erolp catalyzed pathway is depicted in Figure 2. PDIp accepts electrons from the nascent polypeptide chain, resulting in oxidation of the active site cysteines. Erolp itself contains two disulfides that are involved in the transfer of electrons from PDIp to the enzymebound FAD. The first disulfide, termed the shuttle disulfide, accepts electrons from PDIp. The second disulfide within Erolp, which is located close to the FAD group in the crystal structure (Gross et al. 2004), accepts electrons from the shuttle disulfide before passing these on to FAD to form $\mathrm{FADH}_{2}$. This rapidly reacts with molecular oxygen to form hydrogen peroxide, regenerating Erolp for another round of catalysis.

Erolp activity is tightly regulated to ensure a balance of oxidized and reduced PDIp, allowing both the formation and reduction of disulfides in nascent polypeptides (Sevier et al. 2007). This regulation is brought about by the formation of noncatalytic disulfide bonds within Erolp. Breaking of these disulfides, possibly by reduced PDIp, leads to activation of the enzymatic activity. By responding to the redox status of PDIp, Erolp can ensure a balance of reduced and oxidized PDIp is maintained.

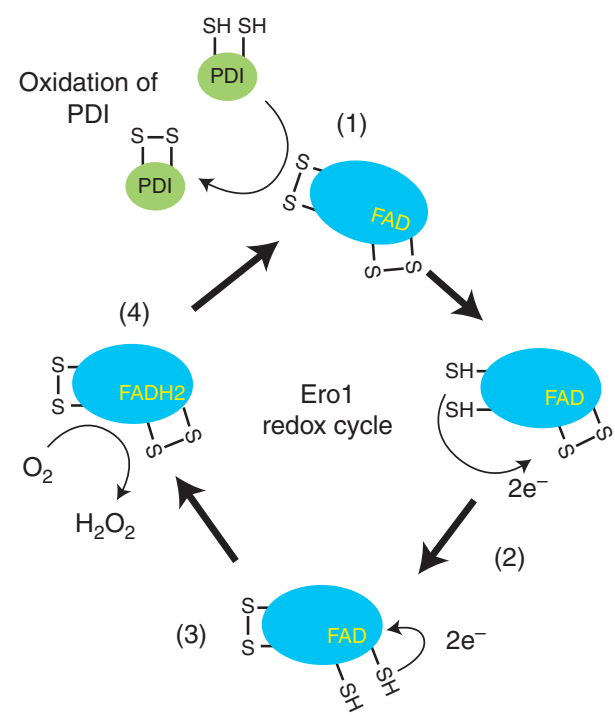

Figure 2. Electron flow following the oxidation of PDI by Ero1. Erol accepts electrons from PDI (1) resulting in the oxidation of PDI and the reduction of the shuttle disulfide within Ero1. An internal disulfide exchange reaction then occurs within Ero1 (2) to transfer electrons to cysteines close to the bound FAD. FAD accepts electrons from the disulfide that is formed (3) and in the process is reduced to form FADH2. Oxygen is the ultimate electron acceptor (4) becoming reduced to liberate hydrogen peroxide.

The situation in mammalian cells is comparable to yeast cells in terms of the regulation of Ero1 (Appenzeller-Herzog et al. 2008; Baker et al. 2008); however, there are two isoforms present (Ero1 $\alpha$ and Ero1 $\beta$ ) that seem to have similar functions but different tissue distribution (Cabibbo et al. 2000; Pagani et al. 2000). In both yeast and mammalian cells the primary enzyme oxidized by Ero1 is PDI itself (Pdip in yeast, PDIA1 in mammals) although other PDI family members may be substrates (Inaba et al. 2010). Importantly, glutathione is a very poor substrate for Ero1 and PDI can be oxidized even in the presence of relatively high concentrations of reduced glutathione ( $\mathrm{Tu}$ et al. 2000). Such kinetic segregation may explain how the oxidation of PDI can occur even in the presence of a reductive pathway.

While Erolp function is essential in yeast, an Ero $1 \alpha /$ Ero $1 \beta$ double mouse knockout is still viable with a relatively mild phenotype (Zito 
N.J. Bulleid

et al. 2010a). Hence, in mammalian cells other pathways are capable of replacing the essential function of Erol.

\section{Peroxiredoxin IV}

The complementation of Erol in mammalian cells is due in part to the presence of ER-localized peroxidases that can act as alternative electron acceptors for PDI and that use hydrogen peroxide as the terminal electron acceptor ( $\mathrm{Ta}$ vender et al. 2008, 2010; Zito et al. 2010b). The most extensively characterized of these peroxidases is peroxiredoxin IV (PrxIV), which belongs to the typical 2-cys peroxiredoxin family of proteins and shares structural homology and a similar mechanism of action with the rest of the family members (Cao et al. 2011; Wang et al. 2012). The first step in its reaction with hydrogen peroxide is the formation of a sulfenylated cysteine at its active site or peroxidatic cysteine (Fig. 3). The second-order rate constant for this reaction is extremely rapid, ensuring the efficient removal of any hydrogen peroxide present in the ER lumen (Wang et al. 2012). PrxIV forms a decamer consisting of five dimers arranged in a donut-like structure (Cao et al. 2011; Wang et al. 2012). Each polypeptide in the dimeric unit contains a peroxidatic cysteine. On sulfenylation there is a conformational change in the dimer resulting in a peroxidatic cysteine being brought into close proximity to a cysteine residue in the adjacent polypeptide chain. This is called the resolving cysteine residue, which reacts with the sulfenylated peroxidatic cysteine to form a disulfide bond. It is this disulfide that can readily accept electrons from PDI resulting in oxidation of the PDI active site disulfide (Tavender et al. 2010). So for every oxygen molecule reduced, one disulfide in PDI will

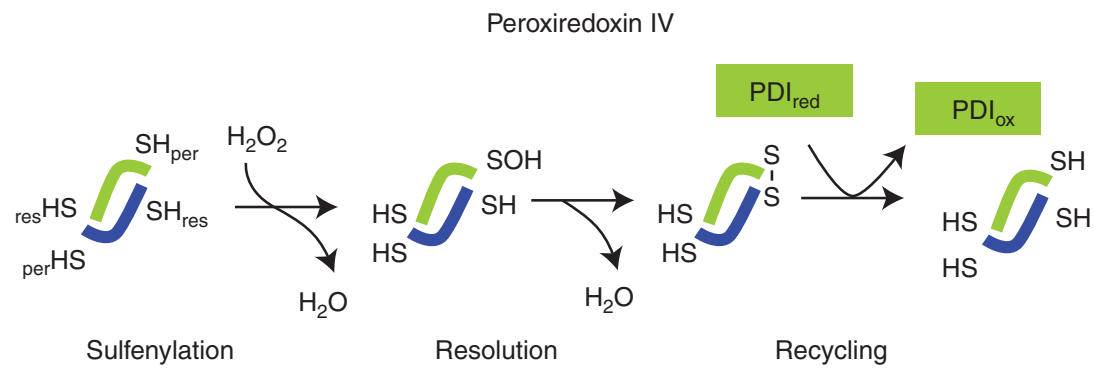

Glutathione peroxidase (Gpx7/8)

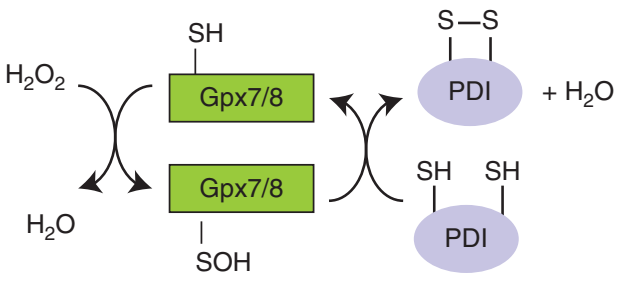

Sulfenylation

Figure 3. Alternative pathways for PDI oxidation involving PrxIV or Gpx7/8. For both pathways the initial reaction is the oxidation of the active site cysteine to form sulfenylated cysteine. This residue is resolved by a second cysteine within an adjacent subunit in PrxIV or within the PDI active site for Gpx7/8. Reduced PDI recycles PrxIV to regenerate a free thiol at the active site of PrxIV and in the process becomes oxidized. Any mixed disulfide formed between PDI and Gpx7/8 will be rapidly resolved by the second cysteine in the PDI active site to form oxidized PDI. The cysteine residues marked "res" and "per" in PrxIV refer to the resolving and peroxidatic cysteines, respectively. 
be formed by Erol and another by PrxIV following the reduction of hydrogen peroxide to water.

The significance of the PrxIV pathway was shown by the fact that mammalian cells lacking both Erol isoforms were able to grow and form disulfides, whereas knockdown of PrxIV in these cells led to markedly attenuated disulfide bond formation and compromised cell growth (Zito et al. 2010b). In addition, the introduction of PrxIV into a yeast strain carrying a temperature-sensitive mutant of Erolp allowed this strain to grow at the nonpermissive temperature. The lethality of an Erol knockout in yeast could be attributable to the absence of a PrxIV homolog in this organism. In mammalian cells, PrxIV could function in concert with Erol and the glutathione peroxidases Gpx7 and 8 to metabolize hydrogen peroxide and to maximize the oxidative power of the reduced oxygen. Even in the absence of Erol activity in the mouse double knockout, PrxIV is able to use hydrogen peroxide produced by alternative mechanisms to drive disulfide formation. The source of this non-Erol-generated hydrogen peroxide has yet to be established. Only PDI, ERp46, and P5 have been shown to be oxidized by PrxIV in vitro and in cells, whereas other PDI family members such as ERp18 and ERp57 are not substrates, demonstrating some specificity in this pathway for oxidation (Tavender et al. 2010).

\section{Glutathione Peroxidases 7 and 8}

In addition to PrxIV there are two further peroxidases localized to the mammalian ER (Raykhel et al. 2007). These are called glutathione peroxidase 7 and 8 (Gpx7 and Gpx8), which have been shown to drive the oxidation of PDI in vitro (Nguyen et al. 2011). Both of these enzymes are actually very poor glutathione peroxidases but have much more enhanced activity as PDI peroxidases. Gpx7 is a soluble protein, whereas Gpx8 is a type I membrane protein. Both contain ER retrieval sequences at their carboxyl termini. The reaction mechanism is thought to involve the oxidation of the catalytic cysteine residue by hydrogen peroxide to form a sulfenylated cysteine. This sulfenylated cysteine can then accept electrons from a PDI family member to form an unstable mixed disulfide between Gpx7/8 and PDI that will be rapidly resolved by the second cysteine in the PDI active site to yield oxidized PDI (Fig. 3). Both enzymes have been shown to associate with Erol by using bimolecular fluorescence complementation (Nguyen et al. 2011). Hence, these enzymes may well be ideally placed to use the hydrogen peroxide produced by Erol to drive the oxidation of PDI. In addition, these enzymes appear to be quite promiscuous in terms of the PDI family members that they can oxidize, at least in vitro.

\section{Vitamin K Epoxide Reductase}

Although the Ero1 and ER peroxidase pathways are probably the main routes for electron flow during disulfide formation, their absence does not preclude animal viability or, indeed, disulfide formation. This realization has become apparent recently following the viability of a mouse strain lacking both Erol isoforms and PrxIV (D Ron, pers. comm.). One potential alternative pathway for driving the oxidation of PDI in the absence of Erol and PrxIV comes from the activity of the enzyme vitamin $\mathrm{K}$ epoxide reductase (VKOR). This membrane-associated enzyme is capable of donating electrons to vitamin $\mathrm{K}$ epoxide and vitamin $\mathrm{K}$ to form vitamin $\mathrm{K}$ hydroquinone (Fig. 4) (Berkner 2008). The latter is used by vitamin K-dependent carboxylase during the $\gamma$-carboxylation of glutamate residues in blood clotting factors. A CXXC motif within a transmembrane domain of VKOR donates electrons to vitamin Kepoxide resulting in the formation of a disulfide bond within VKOR (Rishavy et al. 2011). Electrons are then transferred via an internal disulfide exchange reaction to form a disulfide between two cysteines present to the ER lumenal domain of VKOR. Finally, members of the PDI family are able to donate electrons to VKOR resulting in disulfide formation within the PDI enzyme. Using a substrate-trapping approach, VKOR was shown to preferentially form mixed disulfides with the transmembrane PDI family members TMX and TMX4 as well as the soluble 

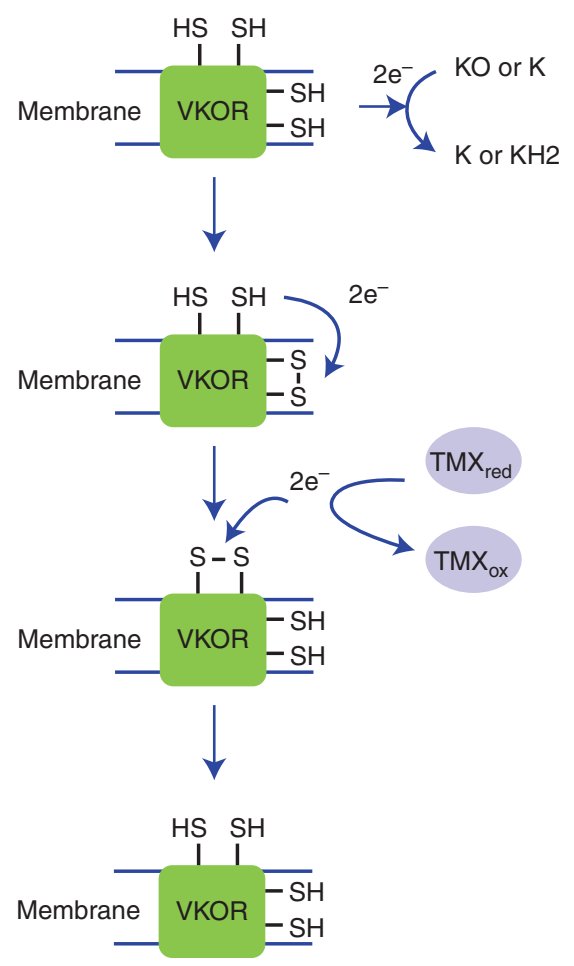

Figure 4. VKOR can also oxidize members of the PDI family. VKOR is a membrane protein that contains two cysteines within a transmembrane helix. These can form a disulfide following the donation of electrons to either vitamin K epoxide (KO) or vitamin $\mathrm{K}$ $(\mathrm{K})$, generating vitamin $\mathrm{K}$ hydroquinone $(\mathrm{KH} 2)$. The resulting disulfide can then exchange with two cysteines present within the luminal domain of VKOR. The resulting disulfide can be reduced by the PDI family members TMX1, TMX4, or ERp18, resulting in the oxidation of these proteins.

protein ERp18 (Schulman et al. 2010). The relative contribution of this pathway to disulfide formation is not clear but it is known that combined knockdown of Erol, PrxIV, and VKOR compromises disulfide formation and causes cell death in a mammalian cell culture system (Rutkevich and Williams 2012).

\section{QSOX}

The quiescin sulfhydryl oxidase (QSOX) pathway differs from the other oxidative pathways in that the enzyme is capable of directly oxidizing polypeptides without the requirement for a disulfide exchange protein such as PDI (Thorpe and Coppock 2007). The enzyme manages this feat by combining a flavoenzyme domain, similar to Ero1, with a thioredoxin domain, similar to PDI. The thioredoxin domain accepts electrons from the polypeptide substrate and passes these electrons ultimately to FAD via two internal disulfide exchange reactions (Heckler et al. 2008). Hence, the enzyme is an efficient disulfide catalyst in vitro able to introduce covalent linkages into a wide range of protein substrates (Hoober et al. 1999). In addition, human QSOX can complement an Ero1-deficient yeast strain, demonstrating that it can fulfill the essential function of yeast Erol at least when overexpressed (Chakravarthi et al. 2007).

There are two aspects of this enzyme that may restrict its function as a disulfide catalyst in the mammalian ER. Most of the intracellular enzyme is localized to the Golgi apparatus with enzyme also being secreted from mammalian cells, so the amount of ER-localized enzyme may be limited. In addition, the enzyme contains a transmembrane domain, which may restrict the catalysis of soluble substrates. The fact that the enzyme is secreted despite its insertion into the ER membrane would suggest that during the secretory pathway it becomes cleaved to release the catalytic ectodomain. The substrates for intracellular or secreted QSOX remain unknown but are likely to include extracellular matrix proteins that require disulfides to be formed or repaired outside the cell.

\section{Other Potential Electron Acceptors}

Other less well characterized pathways may contribute to the oxidation of PDI family members. Included here would be the reduction of dehydroascorbate to generate ascorbate and the recycling of formylglycine-generating enzyme (FGE) (Dierks et al. 2005; Saaranen et al. 2010). The reduction of dehydroascorbate by $\mathrm{PDI}$ is a relatively slow process, making this particular route for PDI oxidation unlikely in the ER. FGE generates the key catalytic residue in the active site of sulfatases and in the process forms a disulfide bond that could be reduced 
by PDI. However, the specialized nature of this posttranslational modification is unlikely to contribute significantly to disulfide formation.

\section{DISULFIDE EXCHANGE PROTEINS}

The PDI family of disulfide exchange proteins plays a central role in ensuring that the correct disulfides are introduced into proteins entering the secretory pathway. These enzymes are able to act as a conduit for electrons from nascent polypeptides to the ER oxidases. In addition they can catalyze electron flow from suitable electron donors, such as glutathione, to facilitate the reduction of disulfides (Freedman et al. 1994). Each enzyme contains at least one thioredoxin domain containing an active site CXXC motif that shuttles between the reduced (dithiol) and oxidized (disulfide) form. Whether the active site cysteines exist in the reduced or oxidized state depends on the stability of the disulfide and the ability of an ER oxidase to catalyze its oxidation (Ellgaard and Ruddock 2005). Unlike cytosolic thioredoxin that acts as an electron donor, most of the PDI family members have active site disulfides that are relatively unstable, making these enzymes poised to act as electron acceptors (Jeong et al. 2008; Chambers et al. 2010). The exception is ERDj5, which has four thioredoxin domains containing CXXC active sites, one of which is relatively stable (Hagiwara et al. 2011). It may well be that this enzyme has a more specialized role in protein reduction during ER-associated degradation requiring an active site disulfide with a lower reduction potential than the other PDI family members.

There are at least 15 PDI family members present in mammalian cells that can act as disulfide exchange proteins (Table 1 ). In addition, several other members of the PDI family exist that contain thioredoxin domains but do not retain both the active site cysteines (Ellgaard and Ruddock 2005). Several of the active enzymes are present at high concentrations in the same tissue (Knoblach et al. 2003; van Anken et al. 2003). Why there are so many potential disulfide exchange proteins is unclear; they may have different substrate specificities or preference for either reduction or oxidation reactions (Hatahet and Ruddock 2007). Substrate specificity has been analyzed by expressing substrate-trapping mutants of the PDI family members (Jessop et al. 2007, 2009; Schulman et al. 2010). For this approach the second cysteine in the CXXC motif is mutated to serine or alanine to prevent the resolution of the normally transient mixed disulfide formed during the reduction reaction. When such mutant proteins are expressed in cells, mixed disulfides formed between the enzyme and substrate can be stabilized by treating cells with a membrane permeable alkylation agent such as $N$-ethyl maleimide (Dick and Cresswell 2002). The resulting complexes are immunoisolated and the identity of the substrates determined by mass spectrometry. The results from this type of approach show that several PDI family members can form mixed disulfides with the same substrate but there is a level of specificity. For example, ERp57 interacts preferentially with glycoprotein substrates (Jessop et al. 2007) and ERp18 with proteins forming interchain disulfides (Jessop et al. 2009). In addition, several PDI family members form mixed disulfides together suggesting that electron transfer can occur between these enzymes. Such a transfer may be necessary if the ER oxidases only oxidize specific PDI proteins.

Although it might seem relevant to determine substrate specificity by assaying the oxidoreductase activity of individual PDI family members using purified enzymes and substrates, it should be understood that within cells it is unlikely that these enzymes function in isolation. The newly synthesized polypeptide chain interacts with several other proteins during translocation into and folding in the ER. These other proteins include enzymes responsible for $N$-linked glycosylation and molecular chaperones such as BiP or Grp94 that bind to hydrophobic regions of the folding polypeptide chain. Members of the PDI family form alliances with some of these proteins to optimize the catalytic process by localizing the enzyme to the nascent chain. The best-studied example of this alliance is between the PDI family member ERp57 and the ER lectins calnexin and calreticulin (Oliver et al. 1997). By associating with these lectins, 
N.J. Bulleid

Table 1. Members of the PDI family active in disulfide exchange

\begin{tabular}{|c|c|c|c|c|c|c|c|}
\hline \multirow{2}{*}{$\begin{array}{l}\text { PDI } \\
\text { family } \\
\text { member }\end{array}$} & \multicolumn{3}{|c|}{ Oxidized by } & \multicolumn{3}{|c|}{ 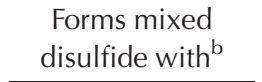 } & \multirow[b]{2}{*}{ Potential function } \\
\hline & Ero1 & PrxIV & Gpx7/8 & Ero1 & PrxIV & VKOR & \\
\hline PDI & Yes & Yes & Yes & Yes & Yes & No & $\begin{array}{l}\text { Formation, isomerization, and reduction of disulfides, } \\
\text { potential chaperone (Wilson et al. 1998), ERAD } \\
\text { (Wahlman et al. 2007) }\end{array}$ \\
\hline ERp57 & Weak & No & Yes & Yes & No & No & $\begin{array}{l}\text { Calnexin/calreticulin-associated oxidoreductase } \\
\text { (Oliver et al. 1997) } \\
\text { Forms a complex with tapasin (Peaper et al. 2005) }\end{array}$ \\
\hline ERp72 & ND & ND & Yes & No & No & No & Potential oxidoreductase (Satoh et al. 2005) \\
\hline P5 & ND & Yes & Yes & Yes & Yes & No & $\begin{array}{l}\text { Potential oxidoreductase (Kramer et al. 2001); } \\
\text { associates with BiP and forms mixed disulfides with } \\
\text { BiP client proteins (Jessop et al. 2009) }\end{array}$ \\
\hline PDIp & ND & ND & ND & ND & ND & No & Pancreas-specific PDI \\
\hline PDIR & ND & ND & ND & ND & ND & No & Potential oxidoreductase (Horibe et al. 2004) \\
\hline ERp46 & ND & Yes & Yes & Yes & Yes & ND & $\begin{array}{l}\text { Protection against ER stress (Sullivan et al. 2003; } \\
\text { Alberti et al. 2009) }\end{array}$ \\
\hline ERp18 & ND & No & No & Yes & No & Yes & Potential oxidase (Jeong et al. 2008; Rowe et al. 2009) \\
\hline ERDj5 & ND & ND & ND & ND & ND & ND & $\begin{array}{l}\text { Potential disulfide reductase involved in ERAD (Dong } \\
\text { et al. 2008; Ushioda et al. 2008) }\end{array}$ \\
\hline TMX1 & ND & ND & ND & ND & ND & Yes & $\begin{array}{l}\text { Protection from stress (Matsuo et al. 2001) } \\
\text { Potential function in quality control (Matsuo et al. } \\
\text { 2009) }\end{array}$ \\
\hline TMX2 & ND & ND & ND & ND & ND & ND & Oxidoreductase (by homology) \\
\hline TMX3 & ND & ND & ND & ND & ND & ND & Potential thiol oxidase (Haugstetter et al. 2005) \\
\hline TMX4 & ND & ND & ND & ND & ND & Yes & Oxidoreductase (by homology) \\
\hline AGR2 & ND & ND & ND & ND & ND & ND & Potential oxidoreductase (Park et al. 2009) \\
\hline TUSC3 & ND & ND & ND & ND & ND & ND & $\begin{array}{l}\text { Homolog of yeast Ost } 3 / 6 \text { Oligosaccharide transferase } \\
\text { subunit involved in glycosylation efficiency (Schulz } \\
\text { et al. 2009) }\end{array}$ \\
\hline
\end{tabular}

PDI, protein disulfide isomerase; VKOR, vitamin K epoxide reductase; ERAD, ER-associated degradation; ND, no data; ER, endoplasmic reticulum.

${ }^{a}$ Inaba et al. 2010; Tavender et al. 2010; Nguyen et al. 2011.

'Jessop et al. 2007, 2009; Schulman et al. 2010.

ERp57 can be localized to glycoproteins that have not folded correctly, thereby allowing disulfide exchange reactions to occur more selectively (Jessop et al. 2007). In addition, ERp57 forms a stable complex with tapasin as part of the MHC class I peptide loading complex (Kienast et al. 2007). Additional alliances between PDI family members and other polypeptide binding proteins include P5 interacting with the Hsp70 homolog BiP (Jessop et al. 2009) and ERDj5 interacting with BiP and EDEM during protein degradation (Ushioda et al. 2008). Additional folding factors may also be recruited to the polypeptide chain folding complex.
These factors include members of the Hsp40 family of cochaperones (Meunier et al. 2002) as well as peptidylproline cis-trans isomerases (Kozlov et al. 2010).

\section{THE REDUCTIVE PATHWAY}

Members of the PDI family are able to catalyze the reduction of disulfides but to do so the active site must be in a reduced state. Consequently, there is a requirement for a pathway of reduction of the PDIs as well as oxidation. Currently there are no candidates for a PDI reductase in the ER lumen. Such a reductase could fulfill a 
similar role that thioredoxin reductase carries out in the cytosol to maintain thioredoxin in a reduced state (Arner 2009). Thioredoxin reductase uses nicotinamide adenine dinucleotide phosphate (NADPH) to drive the reduction reaction. NADPH does exist in the ER where it is generated by the enzyme hexose 6-phosphate dehydrogenase (White et al. 2007). The other major route for reduction in the cytosol is glutathione reductase, which uses the reducing power of NADPH to reduce glutathione disulfide (GSSG) to glutathione (GSH). Although a homolog of glutathione reductase, called ERFAD, does exist, it lacks the catalytic cysteines present in the cytosolic enzyme (Riemer et al. 2009; Shim et al. 2011). However, it does bind FAD and has a conserved NADPH binding site. Apart from an association with the ER-associated degradation machinery, no further indication of a function for ERFAD has been identified.

Whether an enzymatic system for reduction of the PDI disulfide exchange proteins exists in the ER is not clear but we do know that the glutathione redox buffer plays a crucial role in this process and indeed in correct disulfide formation (Chakravarthi and Bulleid 2004; Chakravarthi et al. 2006). If cells are treated with an oxidizing agent then the PDI enzymes become oxidized but are subsequently reduced following removal of the oxidant (Jessop and Bulleid 2004; Appenzeller-Herzog et al. 2010). However, this recovery does not occur when glutathione is depleted from cells. A similar lack of recovery from oxidant treatment can be seen with ER-derived microsomes or semi-intact cells. However, reduction of the PDI proteins does occur if GSH is added to these membrane fractions. These results suggest that GSH, either directly or indirectly, is responsible for reducing PDI enzymes and that this low molecular mass thiol can efficiently pass across the ER membrane. A potential route for reducing the disulfide exchange proteins and to maintaining the ER redox balance would be the transport of GSSG out of the ER to the cytosol where it could be reduced by glutathione reductase. The GSH formed would then pass back into the ER to maintain the ER glutathione concentration and redox balance. This mechanism would require the selective transport of GSSG out of and GSH into the ER by transporter protein(s), which to date have not been identified.

The ability of the ER to recover from either reductive or oxidative changes differs dramatically in the length of recovery time. Cells treated with dithiothrietol (DTT) recover within seconds following the removal of the reductant (Appenzeller-Herzog et al. 2010; van Lith et al. 2011). This recovery is highly dependent on the presence of the Erol pathway, which can be explained by the ability of Erol to metabolize DTT, as well as its activation following the reduction of the regulatory disulfide bonds. Hence, the oxidative pathway rapidly reestablishes a redox balance by an enzymatically driven process. Cells treated with oxidants such as dipyridyl sulfide or diamide recover relatively slowly with full recovery only occurring several minutes after removal of the oxidant (Jessop and Bulleid 2004; Appenzeller-Herzog et al. 2010). Such a slow recovery is more consistent with the requirement for glutathione transport across the ER membrane than an enzymatic process. However, unlike the effect of DTT on Ero1, the oxidant may have a direct effect on any ER reductase inhibiting its activity, thereby preventing a rapid recovery.

In contrast to the situation in mammals, the reductive pathway in the bacterial periplasm is well characterized (Kadokura et al. 2003). Here an enzymatic system exists to ensure the reduction of any nonnative disulfides formed by the action of the oxidative pathway. A pathway involving the passage of electrons across the inner membrane of the periplasm ensures that the thioredoxin homolog DsbC is maintained in a reduced state capable of reducing any nonnative disulfides. The transmembrane protein DsbD donates electrons to DsbC and is itself reduced following the donation of electrons from cytosolic thioredoxin. Each step in the pathway requires a disulfide exchange reaction (Cho et al. 2007). The pathway is kinetically segregated from the oxidative pathway as the main oxidase (DsbB) is unable to oxidize DsbC (Segatori et al. 2004). It is tempting to speculate that a similar system may exist in the mammalian ER. 
N.J. Bulleid

\section{FUTURE PERSPECTIVES}

Since the discovery of Erol there has been increased interest and research into the process of disulfide formation in the ER. We now have a relatively comprehensive view of how disulfides are introduced into proteins and the relative roles of the ER oxidases and disulfide exchange enzymes. However, we still need conclusive evidence for an enzymatic reductive pathway in the mammalian ER or alternative selective transport pathways for GSSG out and GSH into the ER. The next few years may well provide such evidence or may uncover an alternative mechanism for maintaining the ER redox balance. Although many of the individual proteins involved in disulfide formation have been identified the exact roles of many members of the PDI family remain elusive.

Not mentioned in this article is a group of ER resident proteins that may also play a significant role in disulfide formation or reduction. These proteins belong to a larger family of redox active enzyme that contains selenocysteine (Reeves and Hoffmann 2009). Three of the family members - Sep 15, SelM, and SelT-have thioredoxin domains localized to the ER lumen, which contain selenocysteine (U) at a possible CX(1-2)U active site. A fourth protein, SelN, also has an ER localized domain with selenocysteine, although with no obvious homology to thioredoxin. Although many roles for these proteins have been suggested, no definitive function has been shown. It is intriguing to realize that such obvious candidates for ER redox reactive proteins remain poorly characterized, a situation which may well be addressed in the coming few years.

\section{ACKNOWLEDGMENTS}

Support for our work comes from a Scottish Universities Life Science Alliance (SULSA) grant and from the Wellcome Trust grant ref. 88053.

\section{REFERENCES}

Alberti A, Karamessinis P, Peroulis M, Kypreou K, Kavvadas P, Pagakis S, Politis PK, Charonis A. 2009. ERp46 is reduced by high glucose and regulates insulin content in pancreatic $\beta$-cells. Am J Physiol Endocrinol Metab 297: E812-E821.

Appenzeller-Herzog C, Riemer J, Christensen B, Sorensen ES, Ellgaard L. 2008. A novel disulphide switch mechanism in Erol $\alpha$ balances ER oxidation in human cells. EMBO J 27: 2977-2987.

Appenzeller-Herzog C, Riemer J, Zito E, Chin KT, Ron D, Spiess M, Ellgaard L. 2010. Disulphide production by Erol $\alpha$-PDI relay is rapid and effectively regulated. EMBO J 29: 3318-3329.

Arner ES. 2009. Focus on mammalian thioredoxin reductases-Important selenoproteins with versatile functions. Biochim Biophys Acta 1790: 495-526.

Baker KM, Chakravarthi S, Langton KP, Sheppard AM, Lu H, Bulleid NJ. 2008. Low reduction potential of Erol $\alpha$ regulatory disulphides ensures tight control of substrate oxidation. EMBO J 27: 2988-2997.

Berkner KL. 2008. Vitamin K-dependent carboxylation. Vitam Horm 78: 131-156.

Bulleid NJ, Ellgaard L. 2011. Multiple ways to make disulfides. Trends Biochem Sci 36: 485-492.

Cabibbo A, Pagani M, Fabbri M, Rocchi M, Farmery MR, Bulleid NJ, Sitia R. 2000. ERO1-L, a human protein that favors disulfide bond formation in the endoplasmic reticulum. J Biol Chem 275: 4827-4833.

Cao Z, Tavender TJ, Roszak AW, Cogdell RJ, Bulleid NJ. 2011. Crystal structure of reduced and of oxidized peroxiredoxin IV enzyme reveals a stable oxidized decamer and a non-disulfide-bonded intermediate in the catalytic cycle. J Biol Chem 286: 42257-42266.

Chakravarthi S, Bulleid NJ. 2004. Glutathione is required to regulate the formation of native disulfide bonds within proteins entering the secretory pathway. J Biol Chem 279: 39872-39879.

Chakravarthi S, Jessop CE, Bulleid NJ. 2006. The role of glutathione in disulphide bond formation and endoplasmic-reticulum-generated oxidative stress. EMBO Rep 7: $271-275$.

Chakravarthi S, Jessop CE, Willer M, Stirling CJ, Bulleid NJ. 2007. Intracellular catalysis of disulfide bond formation by the human sulfhydryl oxidase, QSOX1. Biochem J 404: 403-411.

Chambers JE, Tavender TJ, Oka OB, Warwood S, Knight D, Bulleid NJ. 2010. The reduction potential of the active site disulfides of human protein disulfide isomerase limits oxidation of the enzyme by Erol $\alpha$. J Biol Chem 285: 29200-29207.

Chen W, Helenius J, Braakman I, Helenius A. 1995. Cotranslational folding and calnexin binding during glycoprotein synthesis. Proc Natl Acad Sci 92: 6229-6233.

Cho SH, Porat A, Ye J, Beckwith J. 2007. Redox-active cysteines of a membrane electron transporter DsbD show dual compartment accessibility. EMBO J 26: 3509-3520.

Dick TP, Cresswell P. 2002. Thiol oxidation and reduction in major histocompatibility complex class I-restricted antigen processing and presentation. Methods Enzymol 348: 49-54.

Dierks T, Dickmanns A, Preusser-Kunze A, Schmidt B, Mariappan M, von Figura K, Ficner R, Rudolph MG. 2005. Molecular basis for multiple sulfatase deficiency and 
mechanism for formylglycine generation of the human formylglycine-generating enzyme. Cell 121: 541-552.

Dixon BM, Heath SH, Kim R, Suh JH, Hagen TM. 2008. Assessment of endoplasmic reticulum glutathione redox status is confounded by extensive ex vivo oxidation. Antioxid Redox Signal 10: 963-972.

Dong M, Bridges JP, Apsley K, Xu Y, Weaver TE. 2008. ERdj4 and ERdj5 are required for endoplasmic reticulum-associated protein degradation of misfolded surfactant protein C. Mol Biol Cell 19: 2620-2630.

Ellgaard L, Ruddock LW. 2005. The human protein disulphide isomerase family: Substrate interactions and functional properties. EMBO Rep 6: 28-32.

Frand AR, Kaiser CA. 1998. The ERO1 gene of yeast is required for oxidation of protein dithiols in the endoplasmic reticulum. Mol Cell 1: 161-170.

Freedman RB, Hirst TR, Tuite MF. 1994. Protein disulphide isomerase: Building bridges in protein folding. Trends Biochem Sci 19: 331-336.

Gross E, Kastner DB, Kaiser CA, Fass D. 2004. Structure of Erolp, source of disulfide bonds for oxidative protein folding in the cell. Cell 117: 601-610.

Hagiwara M, Maegawa K, Suzuki M, Ushioda R, Araki K, Matsumoto Y, Hoseki J, Nagata K, Inaba K. 2011. Structural basis of an ERAD pathway mediated by the ERresident protein disulfide reductase ERdj5. Mol Cell 41: $432-444$.

Hatahet F, Ruddock LW. 2007. Substrate recognition by the protein disulfide isomerases. FEBS J 274: 5223-5234.

Haugstetter J, Blicher T, Ellgaard L. 2005. Identification and characterization of a novel thioredoxin-related transmembrane protein of the endoplasmic reticulum. J Biol Chem 280: 8371-8380.

Heckler EJ, Alon A, Fass D, Thorpe C. 2008. Human quiescin-sulfhydryl oxidase, QSOX1: Probing internal redox steps by mutagenesis. Biochemistry 47: 4955-4963.

Hoober KL, Sheasley SL, Gilbert HF, Thorpe C. 1999. Sulfhydryl oxidase from egg white. A facile catalyst for disulfide bond formation in proteins and peptides. $J$ Biol Chem 274: 22147-22150.

Horibe T, Gomi M, Iguchi D, Ito H, Kitamura Y, Masuoka T, Tsujimoto I, Kimura T, Kikuchi M. 2004. Different contributions of the three CXXC motifs of human proteindisulfide isomerase-related protein to isomerase activity and oxidative refolding. J Biol Chem 279: 4604-4611.

Hwang C, Sinskey AJ, Lodish HF. 1992. Oxidized redox state of glutathione in the endoplasmic reticulum. Science 257: 1496-1502.

Inaba K, Masui S, Iida H, Vavassori S, Sitia R, Suzuki M. 2010. Crystal structures of human Erol $\alpha$ reveal the mechanisms of regulated and targeted oxidation of PDI. EMBO J 29: 3330-3343.

Jansens A, van Duijn E, Braakman I. 2002. Coordinated nonvectorial folding in a newly synthesized multidomain protein. Science 298: 2401-2403.

Jeong W, Lee DY, Park S, Rhee SG. 2008. ERp16, an endoplasmic reticulum-resident thiol-disulfide oxidoreductase: Biochemical properties and role in apoptosis induced by endoplasmic reticulum stress. J Biol Chem 283: $25557-25566$.
Jessop CE, Bulleid NJ. 2004. Glutathione directly reduces an oxidoreductase in the endoplasmic reticulum of mammalian cells. J Biol Chem 279: 55341-55347.

Jessop CE, Chakravarthi S, Garbi N, Hammerling GJ, Lovell S, Bulleid NJ. 2007. ERp57 is essential for efficient folding of glycoproteins sharing common structural domains. EMBO J 26: 28-40.

Jessop CE, Watkins RH, Simmons JJ, Tasab M, Bulleid NJ. 2009. Protein disulphide isomerase family members show distinct substrate specificity: P5 is targeted to BiP client proteins. J Cell Sci 122: 4287-4295.

Kadokura H, Katzen F, Beckwith J. 2003. Protein disulfide bond formation in prokaryotes. Annu Rev Biochem 72: $111-135$.

Kienast A, Preuss M, Winkler M, Dick TP. 2007. Redox regulation of peptide receptivity of major histocompatibility complex class I molecules by ERp57 and tapasin. Nat Immunol 8: 864-872.

Knoblach B, Keller BO, Groenendyk J, Aldred S, Zheng J, Lemire BD, Li L, Michalak M. 2003. ERp19 and ERp46, new members of the thioredoxin family of endoplasmic reticulum proteins. Mol Cell Proteomics 2: 1104-1119.

Kozlov G, Bastos-Aristizabal S, Maattanen P, Rosenauer A, Zheng F, Killikelly A, Trempe JF, Thomas DY, Gehring K. 2010. Structural basis of cyclophilin B binding by the calnexin/calreticulin P-domain. J Biol Chem 285: 35551-35557.

Kramer B, Ferrari DM, Klappa P, Pohlmann N, Soling HD. 2001. Functional roles and efficiencies of the thioredoxin boxes of calcium-binding proteins 1 and 2 in protein folding. Biochem J 357: 83-95.

Matsuo Y, Akiyama N, Nakamura H, Yodoi J, Noda M, Kizaka-Kondoh S. 2001. Identification of a novel thioredoxin-related transmembrane protein. J Biol Chem 276: $10032-10038$.

Matsuo Y, Masutani H, Son A, Kizaka-Kondoh S, Yodoi J. 2009. Physical and functional interaction of transmembrane thioredoxin-related protein with major histocompatibility complex class I heavy chain: Redox-based protein quality control and its potential relevance to immune responses. Mol Biol Cell 20: 4552-4562.

Meunier L, Usherwood YK, Chung KT, Hendershot LM 2002. A subset of chaperones and folding enzymes form multiprotein complexes in endoplasmic reticulum to bind nascent proteins. Mol Biol Cell 13: 4456-4469.

Molteni SN, Fassio A, Ciriolo MR, Filomeni G, Pasqualetto E, Fagioli C, Sitia R. 2004. Glutathione limits Erol-dependent oxidation in the endoplasmic reticulum. J Biol Chem 279: 32667-32673.

Nguyen VD, Saaranen MJ, Karala AR, Lappi AK, Wang L, Raykhel IB, Alanen HI, Salo KE, Wang CC, Ruddock LW 2011. Two endoplasmic reticulum PDI peroxidases increase the efficiency of the use of peroxide during disulfide bond formation. J Mol Biol 406: 503-515.

Oliver JD, van der Wal FJ, Bulleid NJ, High S. 1997. Interaction of the thiol-dependent reductase ERp57 with nascent glycoproteins. Science 275: 86-88.

Pagani M, Fabbri M, Benedetti C, Fassio A, Pilati S, Bulleid NJ, Cabibbo A, Sitia R. 2000. Endoplasmic reticulum oxidoreductin 1-L $\beta(E R O 1-L \beta)$, a human gene induced in the course of the unfolded protein response. J Biol Chem 275: 23685-23692. 
N.J. Bulleid

Park SW, Zhen G, Verhaeghe C, Nakagami Y, Nguyenvu LT, Barczak AJ, Killeen N, Erle DJ. 2009. The protein disulfide isomerase AGR2 is essential for production of intestinal mucus. Proc Natl Acad Sci 106: 6950-6955.

Peaper DR, Wearsch PA, Cresswell P. 2005. Tapasin and ERp57 form a stable disulfide-linked dimer within the MHC class I peptide-loading complex. EMBO J 24: 3613-3623.

Pollard MG, Travers KJ, Weissman JS. 1998. Erolp: A novel and ubiquitous protein with an essential role in oxidative protein folding in the endoplasmic reticulum. Mol Cell 1: $171-182$.

Raykhel I, Alanen H, Salo K, Jurvansuu J, Nguyen VD, Latva-Ranta M, Ruddock L. 2007. A molecular specificity code for the three mammalian KDEL receptors. J Cell Biol 179: $1193-1204$

Reeves MA, Hoffmann PR. 2009. The human selenoproteome: Recent insights into functions and regulation. Cell Mol Life Sci 66: 2457-2478.

Riemer J, Appenzeller-Herzog C, Johansson L, Bodenmiller B, Hartmann-Petersen R, Ellgaard L. 2009. A luminal flavoprotein in endoplasmic reticulum-associated degradation. Proc Natl Acad Sci 106: 14831-14836.

Rishavy MA, Usubalieva A, Hallgren KW, Berkner KL. 2011. Novel insight into the mechanism of the vitamin K oxidoreductase (VKOR): Electron relay through Cys43 and Cys51 reduces VKOR to allow vitamin $\mathrm{K}$ reduction and facilitation of vitamin K-dependent protein carboxylation. J Biol Chem 286: 7267-7278.

Rowe ML, Ruddock LW, Kelly G, Schmidt JM, Williamson RA, Howard MJ. 2009. Solution structure and dynamics of ERp18, a small endoplasmic reticulum resident oxidoreductase. Biochemistry 48: 4596-4606.

Rutkevich LA, Williams DB. 2012. Vitamin K epoxide reductase contributes to protein disulfide formation and redox homeostasis within the endoplasmic reticulum. Mol Biol Cell 23: 2017-2027.

Saaranen MJ, Karala AR, Lappi AK, Ruddock LW. 2010. The role of dehydroascorbate in disulfide bond formation. Antioxid Redox Signal 12: 15-25.

Satoh M, Shimada A, Keino H, Kashiwai A, Nagai N, Saga S, Hosokawa M. 2005. Functional characterization of 3 thioredoxin homology domains of ERp72. Cell Stress Chaperones 10: $278-284$.

Schulman S, Wang B, Li W, Rapoport TA. 2010. Vitamin K epoxide reductase prefers ER membrane-anchored thioredoxin-like redox partners. Proc Natl Acad Sci 107: 15027-15032.

Schulz BL, Stirnimann CU, Grimshaw JP, Brozzo MS, Fritsch F, Mohorko E, Capitani G, Glockshuber R, Grutter MG, Aebi M. 2009. Oxidoreductase activity of oligosaccharyltransferase subunits Ost3p and Ost6p defines site-specific glycosylation efficiency. Proc Natl Acad Sci 106: 11061-11066.

Schwertassek U, Balmer Y, Gutscher M, Weingarten L, Preuss M, Engelhard J, Winkler M, Dick TP. 2007. Selective redox regulation of cytokine receptor signaling by extracellular thioredoxin-1. EMBO J 26: 3086-3097.

Segatori L, Paukstelis PJ, Gilbert HF, Georgiou G. 2004 Engineered DsbC chimeras catalyze both protein oxidation and disulfide-bond isomerization in Escherichia coli:
Reconciling two competing pathways. Proc Natl Acad Sci 101: 10018-10023.

Sevier CS, Qu H, Heldman N, Gross E, Fass D, Kaiser CA. 2007. Modulation of cellular disulfide-bond formation and the ER redox environment by feedback regulation of Ero1. Cell 129: 333-344.

Shim S, Lee W, Chung H, Jung YK. 2011. Amyloid $\beta$-induced FOXRED2 mediates neuronal cell death via inhibition of proteasome activity. Cell Mol Life Sci 68: 2115-2127.

Sullivan DC, Huminiecki L, Moore JW, Boyle JJ, Poulsom R, Creamer D, Barker J, Bicknell R. 2003. EndoPDI, a novel protein-disulfide isomerase-like protein that is preferentially expressed in endothelial cells acts as a stress survival factor. J Biol Chem 278: 47079-47088.

Tavender TJ, Sheppard AM, Bulleid NJ. 2008. Peroxiredoxin IV is an endoplasmic reticulum-localized enzyme forming oligomeric complexes in human cells. Biochem J 411: 191- 199.

Tavender TJ, Springate JJ, Bulleid NJ. 2010. Recycling of peroxiredoxin IV provides a novel pathway for disulphide formation in the endoplasmic reticulum. $E M B O J \mathbf{2 9}$ 4185-4197.

Thorpe C, Coppock DL. 2007. Generating disulfides in multicellular organisms: Emerging roles for a new flavoprotein family. J Biol Chem 282: 13929-13933.

Tu BP, Ho-Schleyer SC, Travers KJ, Weissman JS. 2000. Biochemical basis of oxidative protein folding in the endoplasmic reticulum. Science 290: 1571-1574.

Ushioda R, Hoseki J, Araki K, Jansen G, Thomas DY, Nagata K. 2008. ERdj5 is required as a disulfide reductase for degradation of misfolded proteins in the ER. Science 321: 569-572.

van Anken E, Romijn EP, Maggioni C, Mezghrani A, Sitia R, Braakman I, Heck AJ. 2003. Sequential waves of functionally related proteins are expressed when $B$ cells prepare for antibody secretion. Immunity 18: 243-253.

van Lith M, Tiwari S, Pediani J, Milligan G, Bulleid NJ. 2011. Real-time monitoring of redox changes in the mammalian endoplasmic reticulum. J Cell Sci 124: 2349-2356.

Wahlman J, DeMartino GN, Skach WR, Bulleid NJ, Brodsky JL, Johnson AE. 2007. Real-time fluorescence detection of ERAD substrate retrotranslocation in a mammalian in vitro system. Cell 129: 943-955.

Wang X, Wang L, Sun F, Wang CC. 2012. Structural insights into the peroxidase activity and inactivation of human peroxiredoxin 4. Biochem J 441: 113-118.

White PC, Rogoff D, McMillan DR, Lavery GG. 2007. Hexose 6-phosphate dehydrogenase (H6PD) and corticosteroid metabolism. Mol Cell Endocrinol 265-266: 89-92.

Wilson R, Lees JF, Bulleid NJ. 1998. Protein disulfide isomerase acts as a molecular chaperone during the assembly of procollagen. J Biol Chem 273: 9637-9643.

Zito E, Chin KT, Blais J, Harding HP, Ron D. 2010a. ERO1- $\beta$, a pancreas-specific disulfide oxidase, promotes insulin biogenesis and glucose homeostasis. J Cell Biol 188: $821-832$.

Zito E, Melo EP, Yang Y, Wahlander A, Neubert TA, Ron D. 2010b. Oxidative protein folding by an endoplasmic reticulum-localized peroxiredoxin. Mol Cell 40: 787-797. 


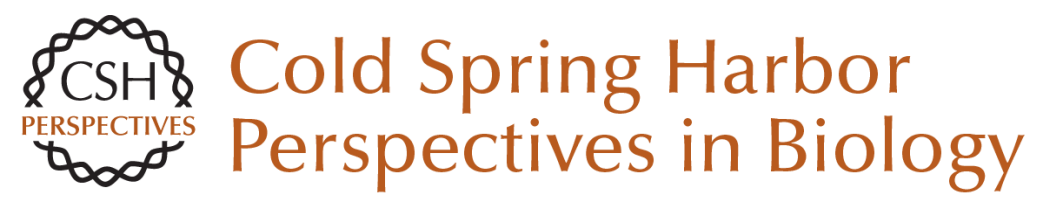

\section{Disulfide Bond Formation in the Mammalian Endoplasmic Reticulum}

Neil J. Bulleid

Cold Spring Harb Perspect Biol 2012; doi: 10.1101/cshperspect.a013219

Subject Collection The Endoplasmic Reticulum

Sorting and Export of Proteins at the Endoplasmic Reticulum

Ishier Raote, Sonashree Saxena and Vivek Malhotra

Endoplasmic Reticulum Membrane Contact Sites, Lipid Transport, and Neurodegeneration Andrés Guillén-Samander and Pietro De Camilli

AMPylation and Endoplasmic Reticulum Protein Folding Homeostasis

Luke A. Perera and David Ron

The Endoplasmic Reticulum and the Fidelity of Nascent Protein Localization

Michael J. McKenna and Sichen Shao

Endoplasmic Reticulum Architecture and Inter-Organelle Communication in Metabolic Health and Disease

Ana Paula Arruda and Günes Parlakgül

Regulation and Functions of the ER-Associated

Nrf1 Transcription Factor

Gary Ruvkun and Nicolas Lehrbach

Mechanism of Protein Translocation by the Sec61

Translocon Complex

Samuel Itskanov and Eunyong Park

Evolutionary Aspects of the Unfolded Protein

Response

Kazutoshi Mori
Glycerolipid Synthesis and Lipid Droplet

Formation in the Endoplasmic Reticulum

Robert V. Farese, Jr. and Tobias C. Walther

The Biogenesis of Multipass Membrane Proteins Luka Smalinskaite and Ramanujan S. Hegde

A TAle of Two Pathways: Tail-Anchored Protein Insertion at the Endoplasmic Reticulum Alina Guna, Masami Hazu, Giovani Pinton Tomaleri, et al.

Cholesterol Transport to the Endoplasmic

Reticulum John P. Kennelly and Peter Tontonoz

The Role of the Rhomboid Superfamily in ER

Protein Quality Control: From Mechanisms and

Functions to Diseases

Satarupa Bhaduri, Nicola A. Scott and Sonya E. Neal

ER-Phagy: Quality and Quantity Control of the

Endoplasmic Reticulum by Autophagy Haruka Chino and Noboru Mizushima

Structure and Function of the Nuclear Pore Complex

Stefan Petrovic, George W. Mobbs, Christopher J. Bley, et al.

Post-Translational Regulation of HMG CoA

Reductase

Youngah Jo and Russell A. DeBose-Boyd

For additional articles in this collection, see http://cshperspectives.cshlp.org/cgi/collection/

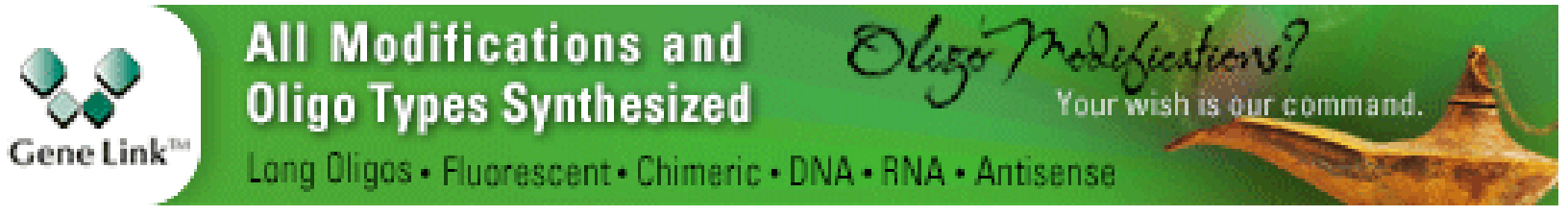


For additional articles in this collection, see http://cshperspectives.cshlp.org/cgi/collection/

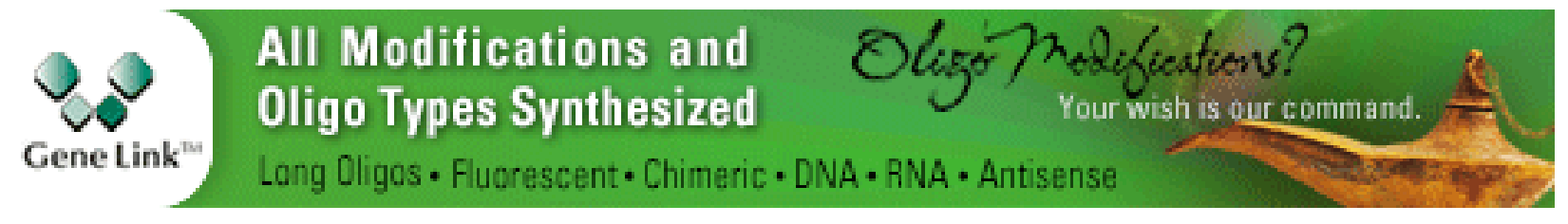

Copyright @ 2012 Cold Spring Harbor Laboratory Press; all rights reserved 